\title{
Los gremios y la política ${ }^{l}$
}

La política o lo político tiene, al menos, dos sentidos: el primero es un sentido global que se remonta al origen etimológico del término, esto es, el interés por la sociedad o por la polis, entre los griegos. En esta acepción lo político es todo empeño en pro del bien común, como puede ser la promoción de la justicia, de los derechos humanos individuales y sociales, del derecho al trabajo, a condiciones de vida dignas, a la educación, a la salud, preocupación por las cuestiones del medio ambientales, de género, de la niñez, etc.

Y el segundo, mucho más restringido, es el campo de la actividad humana destinada a administrar o transformar la sociedad mediante la conquista y el ejercicio del poder del Estado. En este sentido, la política está reservada, exclusivamente, por nuestra Constitución, a los partidos políticos. Esto seguramente, se explica por el momento político en el que se dio esta disposición constitucional, la cual, ciertamente, es discutible pero preferimos centrarnos en analizar las posibilidades del quehacer político autorizado por nuestra legislación vigente.

Partamos de la siguiente hipótesis: todos hacemos política, por acción o por omisión. Ya sea de manera individual u organizada. Por ejemplo, Monseñor Romero hacía política de manera activa, en el sentido amplio del término, cuando denunciaba la injusticia estructural presente en nuestra sociedad; en cambio, el arzobispo Sáenz Lacalle hace política de manera pasiva, es decir, por omisión, cuando calla la realidad injusta de nuestra sociedad.

La política por omisión, esto es, cuando no intervenimos en cuestiones políticas, es la peor forma de hacer política. Si pensamos en uno de los momentos del quehacer político, no el único, obviamente, pero sí uno muy importante, como es el momento electoral y no participamos en él, permitimos que la mayoría de la minoría que votó, o sea, la minoría, sea la que decida sobre cuestiones tan transcendentales como el modelo económico, por ejemplo, o sobre cosas más concretas como la privatización, la apertura comercial, etc. Resulta, obvio, que el hacer política por omisión es la peor forma de hacer política.

Otra obviedad es que los esfuerzos o las luchas de los individuos en tanto que individuos y no en tanto que representantes de una institución son intranscendentes porque se atomizan, se vuelven tan insignificantes que a nadie le preocupan. De nada sirve que los trabajadores del campo y de la ciudad, de manera individual, manifiesten su descontento ante el cúmulo de problemas que enfrentan. Así no se cambia nada. Los microempresarios, por ejemplo, han sido víctimas de todo y de todos: de los precios bajos de sus productos, de los precios altos de los insumos, de las elevadas tasas de interés, de los agiotistas, de los "coyotes", del gobierno, etc. Pero al estar desorganizados no han tenido ni siquiera voz.

Al organizarse comienzan a ser oídos, pero no necesariamente a ser tomados en cuenta. Sus opiniones, sus problemas, sus propuestas, etc., se oyen, pero en demasiadas ocasiones se les ha respondido con demagogia, o bien, han sido sencillamente instrumentalizados por los partidos, por el gobierno o por las poderosas gremiales empresariales e inclusive, por sus mismas cúpulas dirigentes. 
¿Qué hacer entonces? ¿Olvidarse de la política? ¿Hacer política por omisión? Pienso que no. Definitivamente, no.

Los gremios deben de hacer política... ¡Pero qué estoy diciendo! Los gremios hacen política, ¿o acaso la Asociación Nacional de la Empresa Privada no hace política? Lo que ocurre es que hay gremios de gremios. Están los que nos han gobernado indirectamente y están los otros, los gobernados, a los que llamaremos gremios populares. Si éstos van a hacer política, necesitan recuperar su voz a todos los niveles. Así como recuperar o conseguir su autonomía, lo cual implica reconocer su carácter de sujetos de y en la historia y actuar consecuentemente.

Segundo, es necesario hacer política de manera activa, lo cual no significa hacer política partidaria, sino participar activamente en los asuntos públicos que les atañen directa o indirectamente, e inclusive, ser solidarios con otros gremios u otros sectores populares. Esto tampoco significa que se vaya a sustituir a los partidos políticos, pero sí invertir los términos de la relación partido-gremio. No son los partidos políticos los que le van a decir al gremio qué hacer, sino que el partido político, que busque ser representativo, debe asumir como propio lo que los gremios le propongan, o de manera más general, lo que la sociedad popular organizada le indique. El partido político que así actúe, se ganará su legitimidad como representante de los intereses de los sectores populares.

Y tercero, es indispensable tener clara la relación entre el gremio y el partido, la cual presenta, al menos, tres momentos: el de la cotidianidad, el de la coyuntura y el electoral.

En el momento cotidiano, el de todos los días, el gremio realiza su labor propia, independientemente, de los partidos políticos. Hace valer su propia autonomía, pronunciándose, denunciando, exigiendo, etc., lo cual nos indica que no existe una vinculación orgánica con los partidos. Eso que a menudo se decía, o que inclusive se dice aún, "es que ésos son del PDC, o del FMLN o de ARENA", debe de ser cosa del pasado, el gremio es de y para sus agremiados, primaria y fundamentalmente.

En el momento coyuntural cabe la posibilidad de actuar de manera conjunta con uno o más partidos, con los que quieran acompañar al gremio o a los gremios en una determinada acción, que exija de la mayor concurrencia posible de fuerzas sociales y políticas, cualesquiera que éstas sean. Por ejemplo, cuando se rechazó el incremento del impuesto al valor agregado hubo una acción política conjunta y unificada de distintos gremios y partidos políticos, la cual pudo haber sido exitosa de no existir la "politiquería", un tercer sentido de la política, de la cual ni siquiera hemos querido ocuparnos, no porque no exista, sino porque no debiera existir. O bien, la exigencia de la no desgravación arancelaria o la necesidad de disminuir las tasas de interés o los reclamos de los gremios agrarios al gobierno para formular una política orientada a reactivar el sector son ejemplos de acciones políticas legítimas de la sociedad civil, las cuales no pueden descalificarse por el simple hecho de considerarlas que se "han politizado". Esta es una práctica habitual del gobierno arenero cuando no desea dar respuestas favorables a las demandas políticas de los sectores organizados.

Por otra parte es importante que la o las iniciativas surjan del gremio o los gremios, o bien que se asuman por convicción, más no como línea partidaria, cuando tuviesen un origen externo al gremio. Así, tenemos que gremios de microempresarios y de otros sectores se han manifestado en defensa de la finca El Espino, en razón de una convicción ecológica, lo cual pone de manifiesto un quehacer político que transciende los intereses puramente gremiales.

El momento electoral admite una subdivisión: el pre-electoral y el electoral. De ambos quizá el más importante es el momento pre-electoral, cuando se deciden las plataformas y los candidatos. Entonces, los gremios pueden negociar contenidos programáticos e incluso candidatos. Estos, por lo general, no deben ser integrantes de los gremios, pero éstos deben aceptarlos o vetarlos. La historia nos muestra que cuando los dirigentes gremiales incursionan en la política partidaria no sólo no se gana un buen político, sino que además se pierde un buen dirigente gremial.

Hasta aquí, la relación entre el partido y el gremio no parece presentar mayores problemas, pero cuando llega el momento electoral, la cuestión ya no es tan sencilla. Sin embargo, en el momento electoral, lo importante parece ser que lo acordado por un determinado gremio, cuente con la aprobación de los agremiados en asamblea general, que sean ellos y no la directiva la que decida qué postura adoptar el día de las elecciones. 


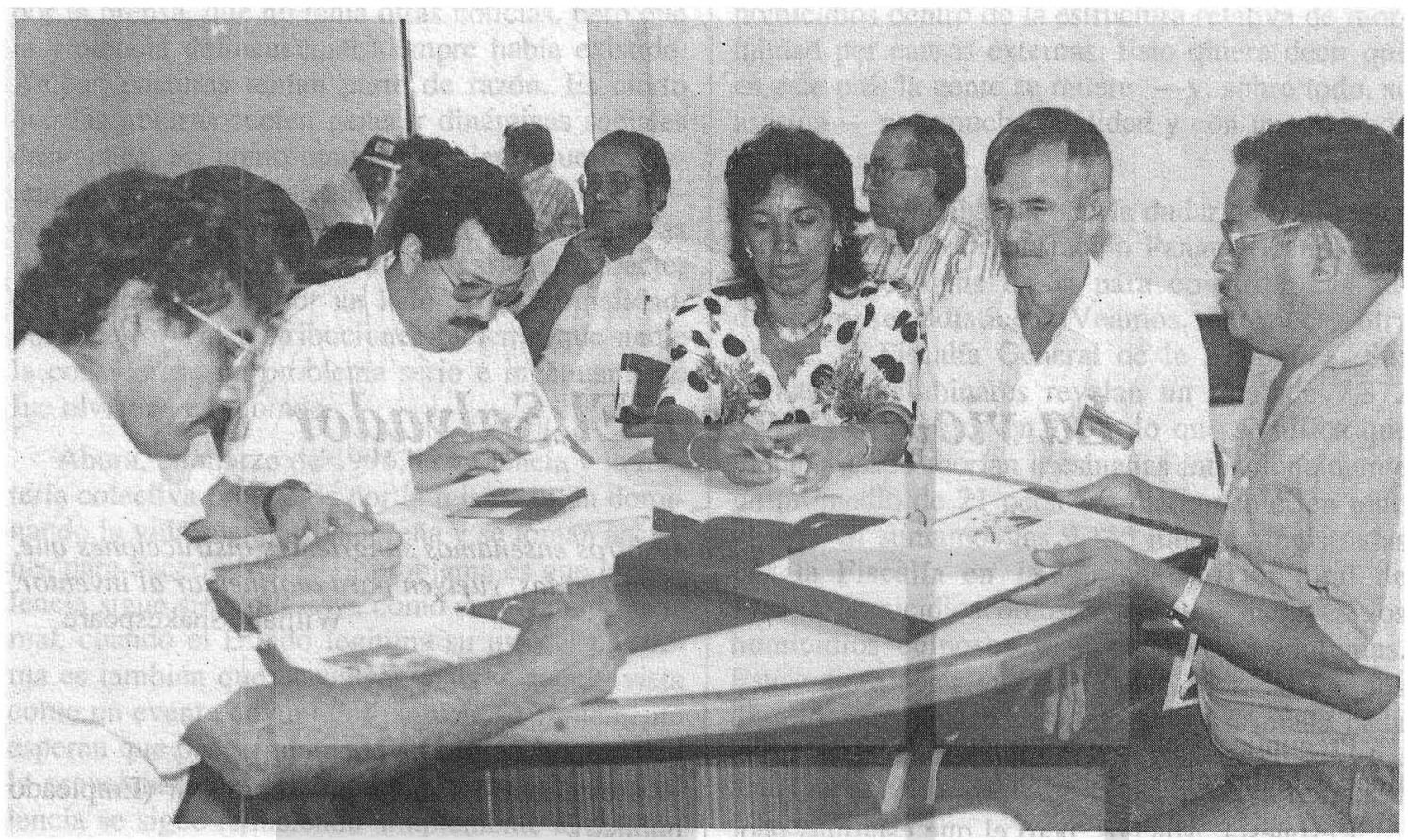

El acuerdo gremial puede ir desde el apoyo público a un determinado partido, la simple orientación del voto, hasta el rechazo a las elecciones cuando resulte fácilmente previsible que no serán libres y limpias, todo lo cual, obviamente, implica un riesgo. Pero, ¿qué en la vida no implica riesgos?

Pero por otra parte, es preciso relativizar los riesgos. Supongamos un caso concreto. Las cooperativas del sector agropecuario reformado para apoyar a un determinado partido político exigen que éste se comprometa a emitir una ley de condonación de la deuda agraria. Sólo hay un partido que acepta esta demanda de los cooperativistas y ese partido, pese al apoyo cooperativista, pierde las elecciones. Los cooperativistas están igual que antes, ¿qué han perdido? En realidad, nada, ya que su única alternativa era que ese partido en particular ganara las elecciones. Como no las ganó, no será posible emitir la ley que los beneficiaría. Pero, ¿qué tal si el partido hubiese ganado las elecciones?

Lo importante en esta cuestión es que los gremios sean fuertes y autónomos. De serlo, los riesgos se minimizan, ya sea que se ganen o pierdan las elecciones. Pero más importante aún es seleccionar correctamente el partido que se decida apoyar, si éste fuese el caso, ya que de lo contrario se podría caer en un juego de gana-pierde. La selección exige, entre otros elementos, conocer la trayectoria política de los diferentes partidos: ¿se trata de un partido de principios o es un partido electorero?, ¿sus dirigentes son personas confiables o se trata de simples oportunistas?, ¿es un partido que tiene compromisos con sectores con los cuales existen intereses divergentes u opuestos o no?, etc.

Como señalábamos, este último elemento es bastante complejo y exige que los gremios, antes de comprometerse en una aventura política, cuenten con la formación y la cultura política que sólo brinda la práctica, la experiencia en la lucha política coyuntural, en la cual los riesgos son mínimos. De modo que el proceso normal de desarrollo político de los gremios es, primero, ganar y fortalecer su autonomía en su quehacer político cotidiano; segundo, manifestar su autonomía en la actividad política coyuntural $y$, finalmente, cuando ya se cuente con la experiencia necesaria, dar algunos pasos cautelosos en la relación entre el gremio y el partido, en el momento electoral.

Aquiles Montoya

1. Ponencia presentada al "Foro nacional sobre gremialización y asociatividad", organizado por la Unión Europea, GTZ, FOMI y AMPES. 